\title{
FATIGUE STRENGTHENING OF CRACKED STEEL PLATES WITH CFRP LAMINATES IN THE CASE OF OLD STEEL MATERIAL
}

\author{
E.Lepretre ${ }^{1}$, S.Chataigner ${ }^{2}$, L.Dieng ${ }^{2}$, L.Gaillet ${ }^{2}$ \\ ${ }^{1}$ CEREMA, DTecITM, CTOA/DGOI, France \\ ${ }^{2}$ LUNAM University, IFSTTAR, MAST Department, SMC Laboratory, France
}

\begin{abstract}
:
This paper reports an experimental study performed to investigate the effectiveness of carbon fiber reinforced polymer (CFRP) laminates in extending fatigue life of old cracked metallic structures. Specimens consist of old metallic plates, mild steel and wrought iron, with one single crack emanating from a rivet hole. This cracking configuration has never been adopted in literature studies and was chosen to be representative of real cracked elements in riveted connections. Two different initial crack lengths before reinforcement, representing two degrees of fatigue damage, were adopted. Four strengthening configurations were investigated including single-sided and double-sided strengthened specimens, Normal Modulus (NM) CFRP plates with or without pre-stressing, and Ultra High Modulus (UHM) CFRP plates. «Beach marking» technique as well as crack gauge were used to monitor and record the crack propagation during fatigue loading. Experimental results show that the application of CFRP plates can effectively reduce the crack growth rate and extend the fatigue life. CFRP plates with high modulus were found to be more efficient. This study represents a contribution to the present state of research and provides some interesting results on crack propagation in CFRP repaired elements close to real riveted ones.
\end{abstract}

Keywords: Fatigue test, wrought iron plate, steel plate, CFRP laminate, strengthening.

\section{INTRODUCTION:}

After corrosion, fatigue phenomenon is the most important cause of damage in old metallic bridges. In France and in Europe, many old railway bridges constructed during 19th and 20th century are now reaching the end of their expected fatigue life [1]. These old structures represent a consistent part of the existing railway bridges and their preservation represents an economical and an environmental issue. Particularities of these old bridges are the constitutive materials, wrought iron and mild steel, and the riveted connections. For riveted beams, fatigue cracks often emanate from the rivet hole in the connection between angle profile and tension flange or angle profile and web plate, which are subjected to tension [2-4]. The traditional repairing method is based on the application of steel plates to the damaged element that are welded (when it is possible), bolted or riveted. This method shows some negative effects such as the introduction of additional permanent loads and new stress concentration areas. Moreover, the additional plates are subjected to the same phenomena of fatigue and corrosion. Application of carbon fiber reinforced polymer (CFRP) laminates to damaged steel elements represents an effective reinforcing technique. These materials have many advantages for their application on steel structures. They show a high tensile strength and rigidity for a low weight as well as a good resistance to corrosion. Some researchers have also demonstrated that the fatigue resistance of the bond under fatigue loading is better than the steel cover plates welded to the cracked element [5-6].

First studies have mainly focused on the static performance of CFRP reinforced structures [7-11]. Then, some research has been conducted on fatigue strengthening of steel structures [12-18]. Both small-scale studies on cracked plates and full-scale studies on steel girders were conducted to assess the efficiency of CFRP strengthening in reducing crack propagation and extending fatigue life. Nevertheless, only a few amount of these studies have focused on the strengthening of old metallic materials such as wrought iron and mild steel. 
Bassetti, [19], investigated the strengthening of center notched mild steel plates and mild steel riveted beams with both prestressed and non-prestressed Normal Modulus (NM) CFRP laminates. Results showed an increase of fatigue life by a factor of 16 when stiffer prestressed CFRP laminates were used. Hansen et al., [20], conducted tests on center notched specimens made from an old mild steel girder and strengthened with both prestressed and non-prestressed CFRP laminates. Again, double-sided strengthened specimens were investigated and various configurations of CFRP laminates and adhesive types were used. It was shown that prestressed CFRP laminates could arrest the crack propagation. Same results were also obtained by Täljsten et al., [21], for center notched standard steel plates with a low prestressing level. Prestressed NM CFRP laminates show therefore great success in fatigue strengthening by introducing compressive stresses and reducing the crack opening displacements. Nonetheless, more studies are still needed to widely used this technique especially regarding the effective transfer of the prestress, the durability and the on site application.

In the last years, others studies have focused on the use of non prestressed CFRP laminates with a higher Young's modulus named High Modulus (HM) and Ultra High Modulus (UHM) CFRP plates. Wu et al., [22], investigated the strengthening of center notched steel plates with UHM CFRP laminates attached on both sides. An increase of fatigue life by a factor ranging from 3.26 to 7.47 depending on the bond length, bond width and bond locations, was reached. The best result is obtained when CFRP plates cover the whole cracked surface. This configuration of reinforcement is not often possible in real cases, especially in riveted connections. Moreover, for such elements, the accessibility to both sides of the damaged elements is not often ensured. Zheng et al., [15], realized tests on CFRP strengthened specimens with NM and UHM CFRP laminates for both single sided and double sided strengthening. The authors show that higher modulus CFRP laminate and double sided strengthening are the most effective for increasing fatigue life. This result regarding the double side repaired configuration was also obtained from various others studies using both CFRP sheets [16, 23] and CFRP plates with normal [24] and ultra high modulus [22].

In all previous studies, central notched specimens consist of metallic plates with a center hole and two symmetric slots at each edge of the hole. These small-scale specimens are not well representative of cracked riveted elements for which more often only one single fatigue crack emanates from the rivet hole. In order to assess the effectiveness of CFRP strengthening old cracked riveted elements, smallscale specimens consisting of old metallic plates with one single crack emanating from a rivet hole were investigated in this paper. Two metallic materials were considered, common mild steel and wrought iron removed from an old girder bridge. Four strengthening configurations were investigated including single side and double side strengthened specimens, Normal Modulus (NM) CFRP plates with or without prestressing, and Ultra High Modulus (UHM) CFRP plates. For wrought iron specimens, only a small amount of material was available for testing so only the best strengthening configuration obtained from mild steel specimens was studied. Two crack-detection methods were used: "beach marking" technique was adopted for mild steel while crack gauges were used for wrought iron specimens. This study represents a contribution to the present state of research and provides some interesting results on crack propagation in CFRP repaired elements close to real riveted ones.

\section{Description of experimental set-up}

\section{a. Test specimens}

24 specimens made of mild steel and 8 specimens made of wrought iron were designed. They correspond to plates of $510 \mathrm{~mm}$ long and $90 \mathrm{~mm}$ wide with a thickness of $10 \mathrm{~mm}$ for mild steel and $7 \mathrm{~mm}$ for wrought iron (web plates thickness). A $20 \mathrm{~mm}$ center hole with a small slot at one edge was realized. The small slot was cut using the erosion technique and a real fatigue crack was generated from it by fatigue loading before the CFRP laminates were applied (more details can be found in [25]).

Two initial lengths of the real fatigue crack generated from the small slot were studied representing two common degrees of damage encountered in real riveted connections:

- A1 7mm corresponding to a crack under rivet head and thus only detectable using nondestructive technique.

- A2 13mm corresponding to a crack emanating from the rivet head and detectable by visual inspection. 
All specimens were reinforced by CFRP laminates of $300 \mathrm{~mm}$ long and $24 \mathrm{~mm}$ wide, bonded at a distance of $10 \mathrm{~mm}$ from the edge of the hole taking into account the presence of the rivet head. Mild steel specimens were patched on one side and both sides, while wrought iron specimens were only patched on one side.

The geometry of the repaired specimens with the different degrees of damage is represented in Fig. 1 .
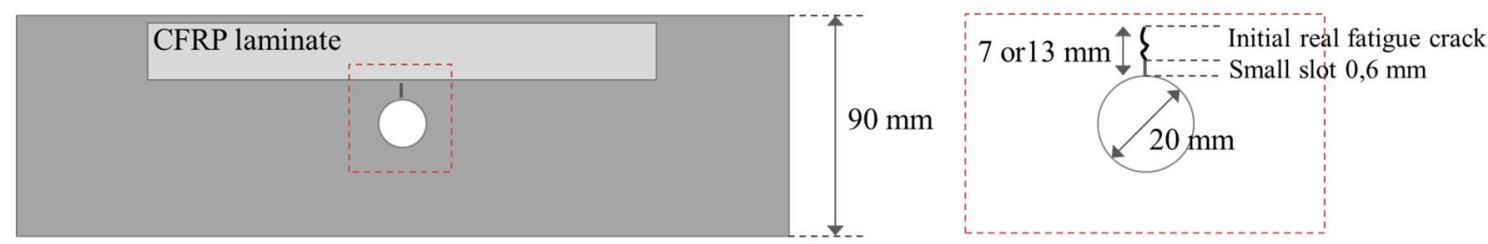

(a) Plan view

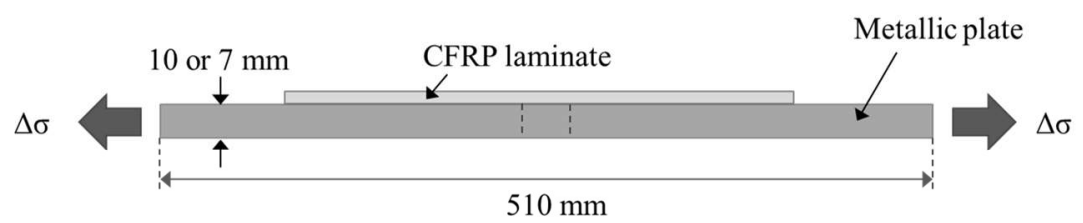

(b) Section view of single-side repaired specimens

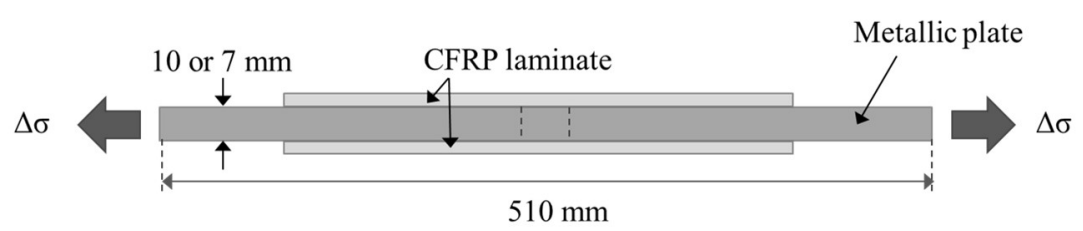

(c) Section view of double-side repaired specimens

Figure 1: Geometry and configuration of the repaired specimens (not to scale)

\section{b. Material properties}

The mechanical properties of the metallic plates were determined through tensile coupon tests. S235 carbon steel grade was used thanks to its properties close to mild steel currently present in old structures $[1,19]$. While wrought iron specimens were fabricated from web plates taken from the dismantling of an old riveted railway bridge shown in Fig.2. The mean yield stress, tensile strength and Young's modulus determined through the tensile tests are given in table 1 .

Table 1: Tensile tests results

\begin{tabular}{|c|c|c|c|c|}
\hline Riveted joint material & $\begin{array}{l}\text { Young modulus } \\
(\mathrm{MPa})\end{array}$ & $\begin{array}{l}\text { Yield strength } \\
(\mathrm{MPa})\end{array}$ & $\begin{array}{l}\text { Ultimate tensile } \\
\text { strength }(\mathrm{MPa})\end{array}$ & $\begin{array}{l}\text { Ultimate tensile } \\
\text { elongation (\%) }\end{array}$ \\
\hline S235 steel plates & $\begin{array}{c}200000 \\
(1480)\end{array}$ & $\begin{array}{l}244 \\
(2.4)\end{array}$ & $\begin{array}{l}507 \\
(3.4)\end{array}$ & $\begin{array}{c}25 \\
(0.25)\end{array}$ \\
\hline $\begin{array}{l}\text { Wrought iron plates } \\
\text { (in rolling direction) }\end{array}$ & $\begin{array}{c}187500 \\
(1400)\end{array}$ & $\begin{array}{l}186 \\
(4.4)\end{array}$ & $\begin{array}{l}307 \\
(5.4)\end{array}$ & $\begin{array}{c}6.5 \\
(0.004)\end{array}$ \\
\hline
\end{tabular}




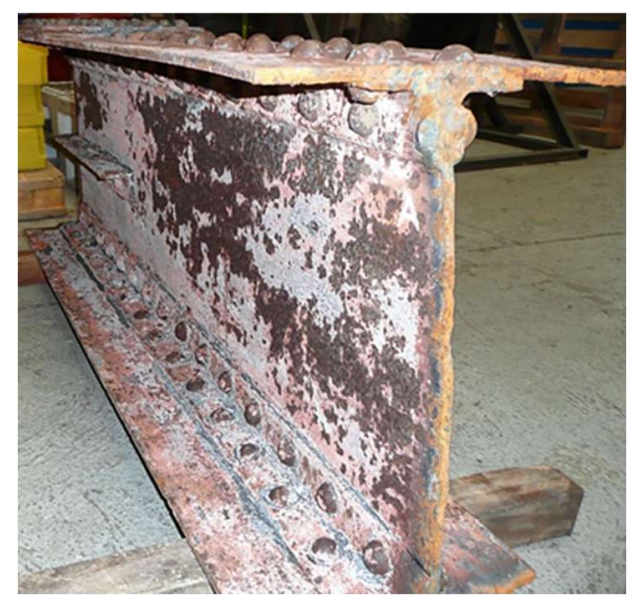

Figure 2: Dismantled Railway Bridge 'Pont de l'Adour' built in 1862

Normal Modulus (NM) and Ultra High Modulus (UHM) CFRP unidirectional plates with their own bicomponent epoxy adhesive were used as the patching systems. According to the manufacturer data, NM plate has an elastic modulus of $165 \mathrm{GPa}$ and a thickness of $1,2 \mathrm{~mm}$, while UHM plate has an elastic modulus of $460 \mathrm{GPa}$ and a thickness of $2,3 \mathrm{~mm}$. More information regarding adhesives and adherents, as well as bonded joint behavior can be found in [26].

\section{c. Specimen preparation}

The bonding surface of the metallic plates were sandblasted, and then carefully cleaned with acetone. Following the manufacturer recommendations, NM CFRP plates were slightly sanded and the peel-ply element was removed from the UHM CFRP plates before bonding on steel. The adhesive was applied uniformly using a brush and a roller was used in order to apply uniform pressure over the CFRP plate. Finally, the specimens were cured for one week in room temperature before being tested. For all specimens, an adhesive joint thickness of less than $1 \mathrm{~mm}$ was observed.

\section{d. Prestressing}

An INSTRON hydraulic jack was used to pre-stress the NM CFRP laminate. A force of $10 \mathrm{kN}$, corresponding to $350 \mathrm{MPa}$ (around $11 \%$ of the ultimate strength of the CFRP plate), was applied to the CFRP plate. Five strain gauges were bonded on the top surface of the laminate in order to record and monitor the pre-stress level first during all the pre-stressing process and then during the fatigue test. Similarly, two strain gauges were bonded on the un-patched side of the metallic plate (on both sides of the hole) in order to record the strain level during the fatigue test. Fig. 3 shows the test set-up and the strain gauges positions. 

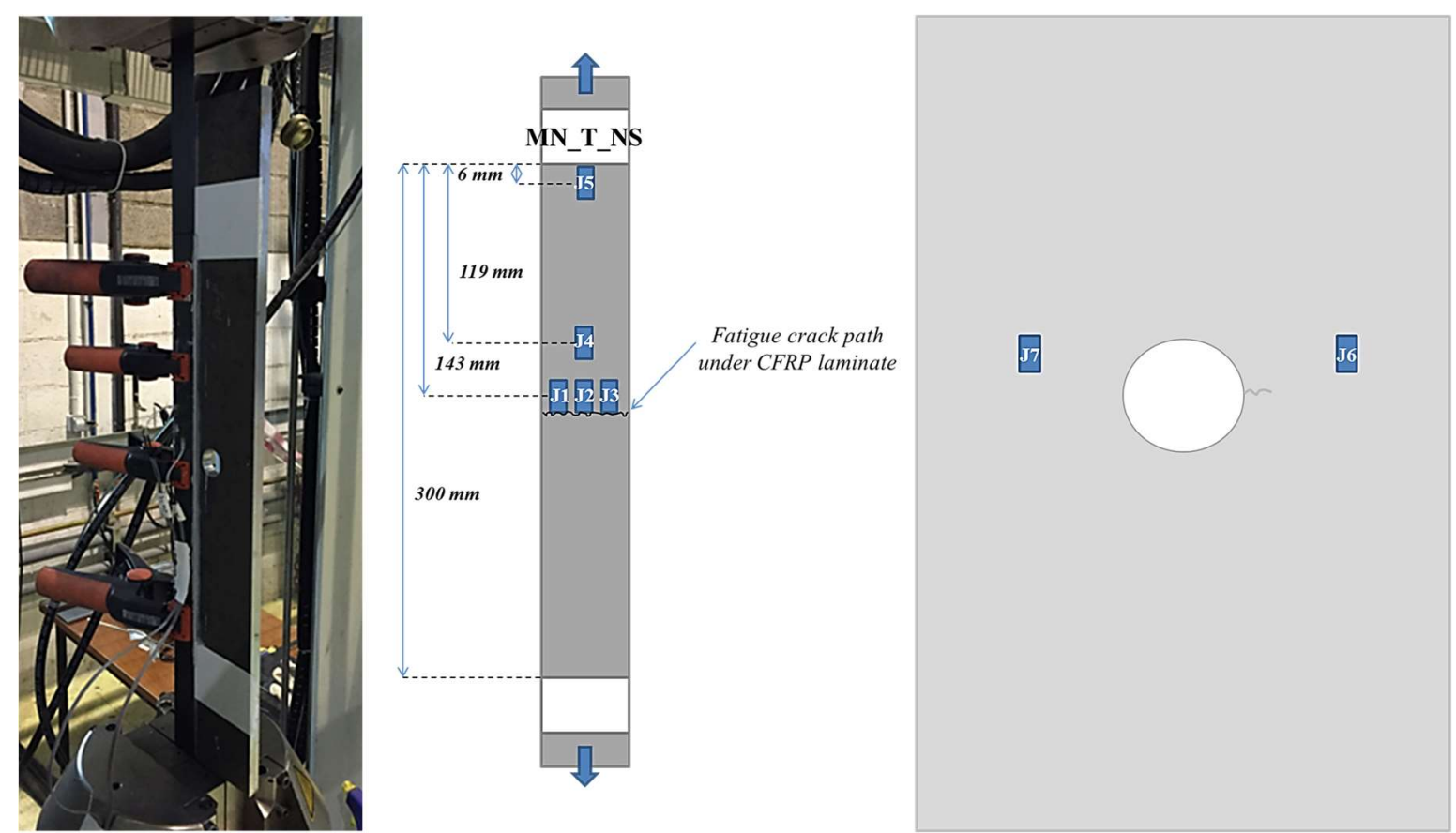

Figure 3: Test set-up and strain gauges position on the CFRP laminate for pre-stressed NM specimens

\section{e. Fatigue loading procedure}

The fatigue tests were carried out on the same INSTRON hydraulic testing machine with a dynamic capacity of $200 \mathrm{kN}$. All specimens were subjected to uniform cyclic loading with a constant frequency of $10 \mathrm{~Hz}$ and a stress ratio $\mathrm{R}$ of 0,1 (commonly used in fatigue testing), until complete failure. The stress ratio is defined as the ratio between the minimum stress to the maximum stress applied to the specimen during the fatigue test. The stress range was the same for all the specimens, $90 \mathrm{MPa}$ in the nominal section. Such a stress range corresponds to an applied load range of 9-90 kN for mild steel specimens (plate $10 \mathrm{~mm}$ thick) and 6,3-63 $\mathrm{kN}$ for wrought iron specimens (plate $7 \mathrm{~mm}$ thick).

\section{f. Measurement of crack propagation}

Crack propagation in the mild steel specimens was followed by the "beach marking" technique [16, 22, $27,28]$, which consists of cyclically reducing the applied stress range for a small number of cycles during the propagation stage of the fatigue crack (cf. Fig.4.a). The reduction in the applied stress range causes changing of stress intensity factor (SIF) value at the crack tip and thus a decrease of the crack growth rate, that leaves visible marks on the crack surface of the material. Observation of real crack size and shape in the thickness of the specimen is then possible after complete failure of the steel plates.

For wrought iron specimens, due to the brittle behavior of the materials, the "beach-marking" technique cannot be applied and crack gauges bonded on the crack path were therefore used. These crack gauges consist of thin measuring grids aligned with interval of $1 \mathrm{~mm}$. Therefore, when the crack grows, it snaps the grids of the crack gauge, one by one, resulting in a change of the electrical resistance and then allowing a precise follow-up of the crack propagation. Fig. 4.b shows a crack gauge bonded on a wrought iron specimen. 


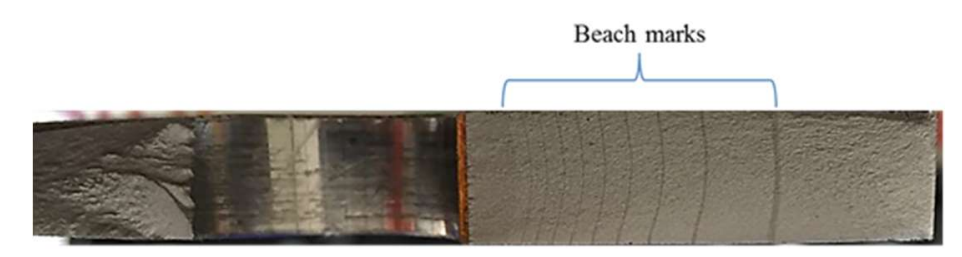

Applied strength $(\mathrm{kN})$

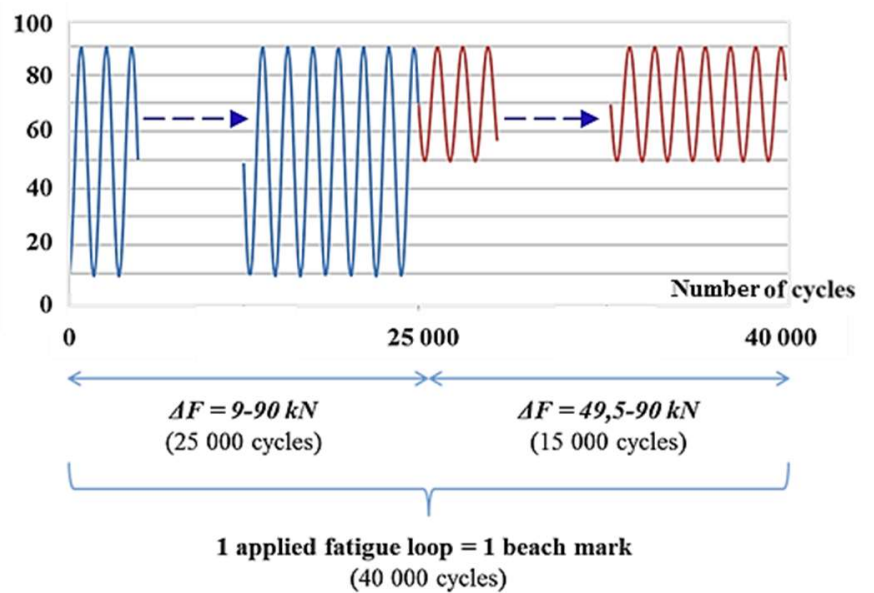

(a) (40 000 cycles)

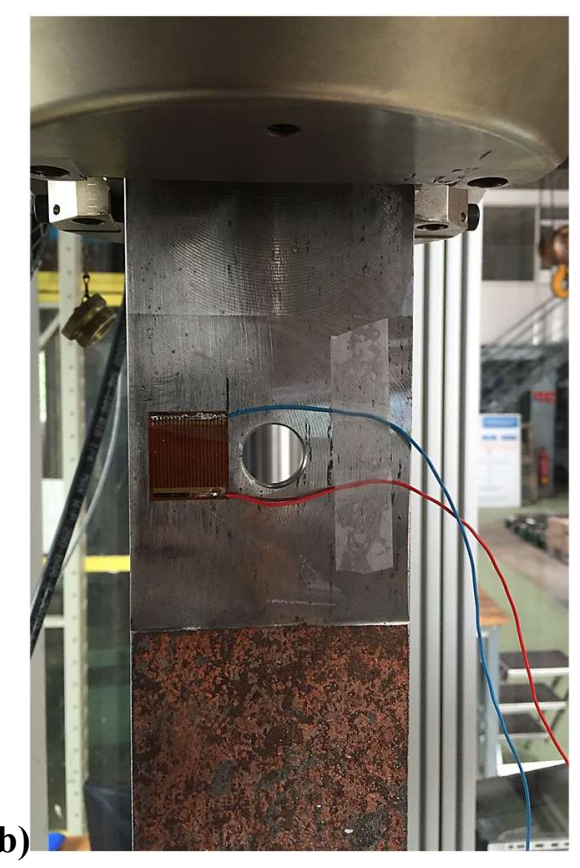

Figure 4: Measurement of crack propagation: (a) 'beach marking' technique for mild steel specimens; (b) crack gauge for wrought iron specimens

\section{Experimental results and discussion}

\section{a. Fatigue life extension}

Details of the specimens and their experimental results are listed in Table 2 and Table 3 for mild steel and wrought iron specimens, respectively. The specimen's designation is as followed: "S/I" refers to S235 carbon steel and wrought iron specimens; "NM/UHM" refers to Normal Modulus and Ultra High Modulus CFRP laminates; "NP/P" refers to non-prestressed and prestressed specimens; "SS/DS" refers to single-side and double-side repaired specimens; and "A1/A2" refers to the initial length of fatigue crack generated before reinforcing.

The indicated fatigue life corresponds to the number of fatigue cycles counted from the initial pre-crack until complete failure of the specimens. In this experimental program, specimens B (mild steel) and C (wrought iron) were tested as reference specimens, without reinforcement.

For mild steel specimens, which shows a good repeatability of the results, the fatigue life of each repaired specimen was compared with the average value of fatigue life of the reference specimens, and the ratio between them is referred to as the fatigue life increase ratio.

However, for wrought iron specimens, for which a wide dispersion of the results was observed, the fatigue life increase ratio was defined as the fatigue life of the repaired specimen divided by the worst fatigue life obtained for the un-reinforced specimens (i.e. maximum value of fatigue life obtained for all reference specimens).

Table 2 : Fatigue test results for mild steel specimens

\begin{tabular}{lcccccc}
\hline & $\begin{array}{c}\text { Specimen } \\
\text { Number }\end{array}$ & $\begin{array}{c}\text { Initial crack } \\
\text { length (mm) }\end{array}$ & $\begin{array}{c}\text { Fatigue life } \\
\text { (cycles) }\end{array}$ & $\begin{array}{c}\text { Fatigue life } \\
\text { increase ratio }\end{array}$ & $\begin{array}{c}\text { Average fatigue } \\
\text { life increase ratio }\end{array}$ & $\begin{array}{c}\text { Failure } \\
\text { mode }\end{array}$ \\
\hline $\begin{array}{l}\text { B (un-reinforced } \\
\text { specimens) }\end{array}$ & -1 & - & 429798 & - & - \\
\hline
\end{tabular}




\begin{tabular}{|c|c|c|c|c|c|c|}
\hline \multirow{3}{*}{ S_NM_NP_SS_A1 } & -1 & \multirow{3}{*}{7} & 487675 & 1,17 & \multirow{3}{*}{$\begin{array}{c}\mathbf{1 , 2 7} \\
(0,064)\end{array}$} & \multirow{3}{*}{$\mathrm{CF}$} \\
\hline & -2 & & 564600 & 1,35 & & \\
\hline & -3 & & 533086 & 1,28 & & \\
\hline \multirow{3}{*}{ S_NM_NP_SS_A2 } & -1 & \multirow{3}{*}{13} & 572913 & 1,37 & \multirow{3}{*}{$\begin{array}{c}\mathbf{1 , 2 5} \\
(0,082)\end{array}$} & \multirow{3}{*}{$\mathrm{CF}$} \\
\hline & -2 & & 497890 & 1,19 & & \\
\hline & -3 & & 489755 & 1,18 & & \\
\hline \multirow{2}{*}{ S_NM_P_SS_A1 } & -1 & \multirow{2}{*}{7} & 770000 & 1,85 & 1,74 & \multirow{2}{*}{$\mathrm{CF}$} \\
\hline & -2 & & 681902 & 1,64 & $(0,105)$ & \\
\hline S_NM_P_SS_A2 & -1 & 13 & 790656 & 1,90 & 1,90 & $\mathrm{CF}$ \\
\hline \multirow{4}{*}{ S_NM_NP_DS_A1 } & -1 & \multirow{4}{*}{7} & 1080215 & 2,59 & \multirow{4}{*}{$\begin{array}{c}\mathbf{2 , 2 7} \\
(0,17)\end{array}$} & \multirow{4}{*}{$\mathrm{CF}$} \\
\hline & -2 & & 902460 & 2,17 & & \\
\hline & -3 & & 958183 & 2,3 & & \\
\hline & -4 & & 849870 & 2,04 & & \\
\hline \multirow{2}{*}{ S_NM_NP_DS_A2 } & -1 & \multirow{2}{*}{13} & 858222 & 2,06 & \multirow{2}{*}{$\begin{array}{c}\mathbf{2} \\
(0,065)\end{array}$} & \multirow{2}{*}{$\mathrm{CF}$} \\
\hline & -2 & & 805992 & 1,93 & & \\
\hline \multirow{3}{*}{ S_UHM_NP_SS_A1 } & -1 & \multirow{3}{*}{7} & 765611 & 1,84 & \multirow{3}{*}{$\begin{array}{c}\mathbf{2 , 1 8} \\
(0,227)\end{array}$} & \multirow{3}{*}{$\mathrm{CF}+\mathrm{CD}$} \\
\hline & -2 & & 1013660 & 2,43 & & \\
\hline & -3 & & 944594 & 2,27 & & \\
\hline \multirow{3}{*}{ S_UHM_NP_SS_A2 } & -1 & \multirow{3}{*}{13} & 658595 & 1,58 & \multirow{3}{*}{$\begin{array}{c}\mathbf{1 , 7 5} \\
(0,184)\end{array}$} & \multirow{3}{*}{$\mathrm{CF}+\mathrm{CD}$} \\
\hline & -2 & & 845338 & 2,03 & & \\
\hline & -3 & & 686301 & 1,65 & & \\
\hline \multirow{2}{*}{ S_UHM_NP_DS_A1 } & -1 & \multirow{2}{*}{7} & 964115 & - & \multirow{2}{*}{-} & \multirow{2}{*}{$\mathrm{CR}$} \\
\hline & -2 & & 1003042 & - & & \\
\hline S UHM NP DS A2 & -1 & 13 & 894311 & - & - & $C R$ \\
\hline 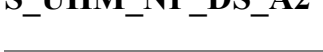 & -2 & 13 & 854651 & - & - & \\
\hline $\mathrm{CF}=$ cohesive fai & adhe & & & & & \\
\hline $\mathrm{CD}=\mathrm{CFRP}$ delan & (se & $f_{\mathrm{s}}$ & rbon fibers & the $m$ & & \\
\hline $\mathrm{CR}=\mathrm{CFRP}$ ruptu & & & & & & \\
\hline The standard deviation & igue & ase & s indicated & ickets & & \\
\hline
\end{tabular}

Table 3: Fatigue test results for wrought iron specimens

\begin{tabular}{lccccc}
\hline & $\begin{array}{c}\text { Specimen } \\
\text { number }\end{array}$ & $\begin{array}{c}\text { Initial crack } \\
\text { length }(\mathrm{mm})\end{array}$ & Fatigue life & $\begin{array}{c}\text { Fatigue life } \\
\text { increase ratio }\end{array}$ & Failure mode \\
\hline C (un-reinforced & -1 & - & 286011 & & - \\
specimens) & -2 & $\sim 6-7$ & 806497 & - & \\
\hline & -1 & $\sim 4$ & 1542085 & 3,79 & CF + CD \\
I_UHM_NP_SS_A1 & -2 & $\sim 4-5$ & 1432910 & 3,53 & \\
& -3 & $\sim 11-12$ & 1074692 & 2,19 & CF + CD \\
\hline & -1 & 1737567 & 4,27 & \\
I_UHM_NP_SS_A2 & -2 & -3 & \\
&
\end{tabular}


The data listed for mild steel specimens (Table 2), show that the fatigue life can be increased by a factor ranging from 1.25 to 2.27 , depending on the reinforcement configuration. The best result was obtained for double-side repaired specimens, as already demonstrated in others studies $[15,16,24]$. For UHM_NP_DS specimens, the fatigue life of the specimens cannot be directly compared with unreinforced ones due to the difference in applied stress range. Actually, for the first UHM_NP_DS reinforced specimen, no failure of the specimen was observed after more than 3 millions cyles. For this reason, the next UHM_NP_DS reinforced specimens were tested under a stress range of $130 \mathrm{MPa}$. Nonetheless, the significant increase in fatigue life, for UHM_NP DS specimens (similar to NM specimens with the same reinforcement configuration), indicates a high efficiency of the reinforcement process.

In case of real reinforced riveted elements, only one side of the assembly is often accessible for reinforcement. Thus, single side repaired specimens seem to be more representative and their associated results more interesting. For NM_NP_SS repaired specimens (no pre-stressed NM CFRP plates), the increase in fatigue lifetime remains low (1.25 for initial crack length A1 and 1.27 for initial crack length A2). Pre-stressed NM CFRP plate before bonding will allow afterwards a huge increase in fatigue lifetime mainly thanks to the increase of the crack closure effects [29]. The average fatigue life increase ratio for these specimens is 1.74 for an initial crack length of $7 \mathrm{~mm}$ (A1) and 1.9 for an initial crack length of $13 \mathrm{~mm}$ (A2). It must be noted that for pre-stressed NM CFRP plate with initial crack A2, only one specimen was tested. The obtained results should be consequently considered with care. Today, the use of NM pre-stressed CFRP plates still raises numerous questions regarding mainly the durability of the bonded joint (losses of pre-stresses with time, stress concentration areas, ...) [30]. For these reasons, UHM CFRP reinforcement seems to be a good alternative, particularly for single-side repaired specimens for which similar or even higher results than pre-stressed ones were obtained: an average increase lifetime of 2.18 was observed for crack length A1 and of 1.75 for crack length A2.

Following these results, only UHM reinforcement process was tested for wrought iron specimens (only a small amount of material was available for testing). In comparison with mild steel, a high dispersion of the results can firstly be noted. This result can be explained by the microstructure of the materials that show a high amount of brittle inclusions inside pure iron. Anyhow, high increase lifetime ratio was obtained for all reinforced specimens ranging from 2.19 to 4.27 . The obtained results for the two materials (mild steel and wrought iron) cannot be compared directly due to the difference in thickness between the specimens (as a reminder, $10 \mathrm{~mm}$ thick for steel and $7 \mathrm{~mm}$ thick for wrought iron). It was shown that CFRP plates have more effect on the stress reduction for thinner plates [16, 28]. Furthermore, it is rather difficult to compare the obtained results with other results from literature studies for two mains reasons: the notch detail in one hand (only one crack at hole edge), and the reinforcement configuration in another hand (CFRP plates bonded neither at both edge of the hole, nor on both sides of the steel plate). Moreover, to our knowledge, no fatigue studies on wrought iron plates reinforced by bonded CFRP plates was done in the literature.

Colombi et al., [31], carried out fatigue tests on cracked steel plates with a center hole and two slots, reinforced with CFRP plates of $500 \mathrm{~mm}$ long, $50 \mathrm{~mm}$ wide and $1.4 \mathrm{~mm}$ thick. Double-side repaired specimens were considered (consisting of CFRP plates bonded at each edge of the hole and on the two sides of the plate), as well as two different Young's modulus CFRP plates (E=174 GPa and E=216 GPa), both prestressed (632 MPa) and non-prestressed. The fatigue test was led under a stress range of $80 \mathrm{MPa}$ with a stress ratio $\mathrm{R}=0,4$. The authors found that the fatigue life was increased by a factor of 5 for prestressed CFRP plates with a Young's modulus of $174 \mathrm{GPa}$. With the same pre-stressing level, but for higher Young's modulus CFRP plates, an increase fatigue lifetime by a factor of 16 was observed. In another study led by Täljsten et al., [21], fatigue strengthening of metallic structures with both prestressed and non-prestressed CFRP plates with Young's modulus of $155 \mathrm{GPa}$ and $260 \mathrm{GPa}$, was investigated. The same specimens geometry was tested under a stress range of $97.5 \mathrm{MPa}$. The results showed that with higher modulus CFRP plates pre-stressed to $12 \mathrm{kN}$ (corresponding to $171 \mathrm{MPa}$ ), the specimen can endure more than 16 millions cycles. For the authors it means that pre-stressed CFRP plates could stop the crack propagation. Recently, Wu et al., [22], compared previous results for CFRP pre-stressing with their own study conducted on UHM CFRP plates with a Young's modulus of 460 
GPa. The cracked steel plates consist of a center hole and two initial slots double side reinforced by CFRP plate with width of $25 \mathrm{~mm}$ close to the dimension used in our study. Constant fatigue loading was applied with a stress range of $135 \mathrm{MPa}$ and a load ratio of 0.1 . For similar reinforcement configuration than previous studies, an average fatigue life extension ratio of 5.82 was obtained. Finally, the authors also studied other CFRP bonding locations and they concluded that CFRP plates should cover the crack or at least be bonded as closed as possible to the crack tip.

\section{b. Crack growth curves}

For mild steel specimens, fatigue crack growth curves can be obtained from the beach marks left on the fracture surface of the material as illustrated in Figure 5.
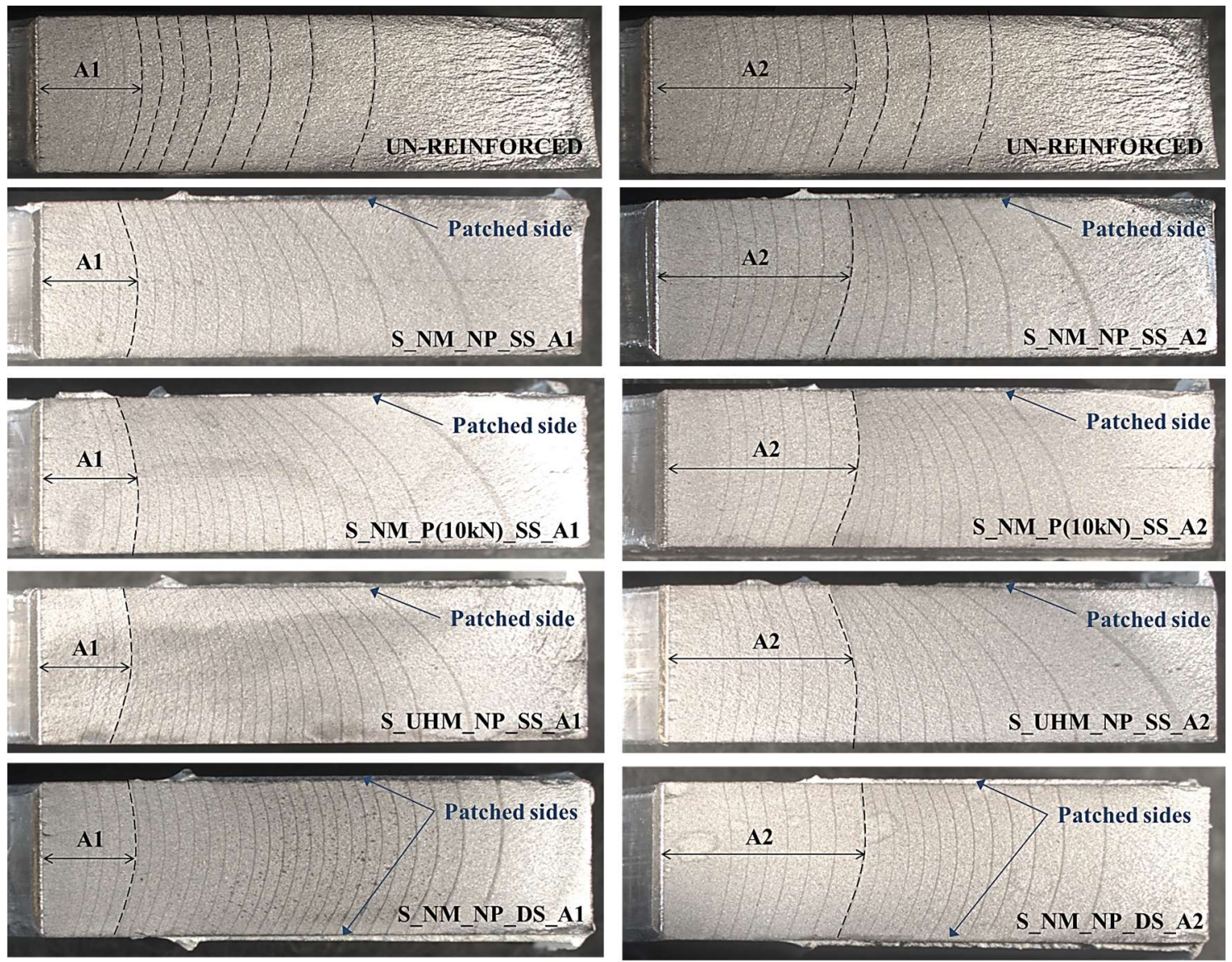

Figure 5: Typical fracture surface with 'beach marks' obtained for both un-strengthened and strengthened mild steel specimens with different reinforcement configuration

Two kinds of crack shapes, symmetric and un-symmetric about the mid-thickness of the plate, were observed depending on the reinforcement configuration. For both un-strengthened and double-side reinforced specimens, all crack front shapes seem almost symmetrically curvilinear, meaning that the crack propagates uniformly on both sides. The slight difference can thus be due to the moment induced by the gripping system of the testing machine or initial material assymetry. For single-side reinforced specimens, however, the crack grows non-uniformly through the thickness of the plate with a much faster crack propagation on the un-patched side. For these specimens, the un-symmetric reinforcement configuration (CFRP bonded only on one side of the steel plate) induces load eccentricity and thus an out-of-plane bending that leads to stress variations over the thickness of the cracked section (variation of the SIF in the thickness) and made the situation worse as the crack propagates [32]. This type of observation for both double-side and single-side reinforced specimens was ever done in others studies using the "beach marking" technique on steel plates [16, 22]. 
For all strengthened specimens, more beach marks are visible on the fracture surface compared with unstrengthened specimens, which means an effective decrease of the crack propagation rate and thus highlights the effectiveness of the CFRP reinforcement.

In order to have a better understanding of the fatigue test results, the crack length versus fatigue life of some specimens were extracted from the beach marks locations. These results are shown in figure 6 for mild steel specimens. For all specimens, crack length is determined at mid-thickness of the plate whatever the reinforcement configuration (symmetric and un-symmetric one).

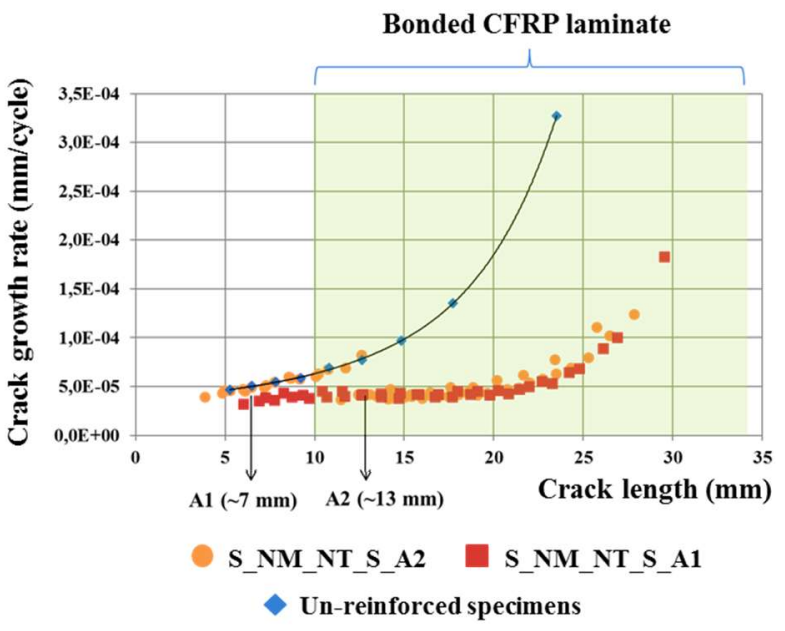

(a)

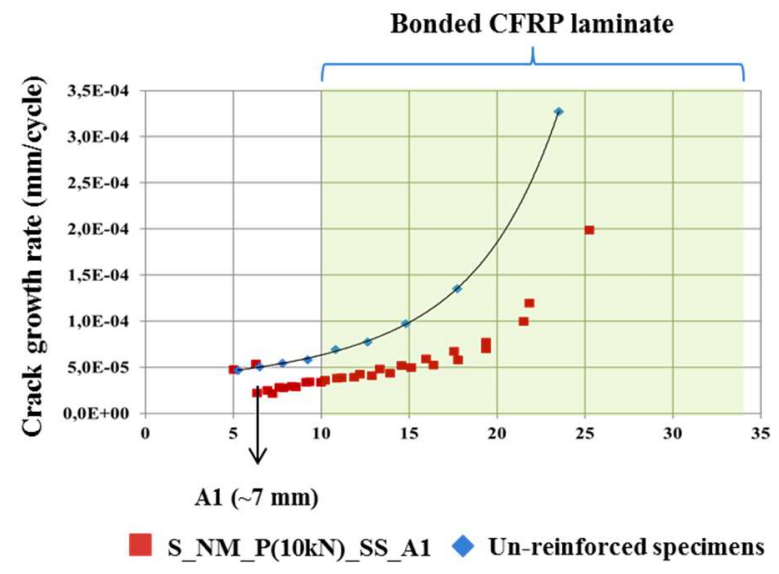

(c)

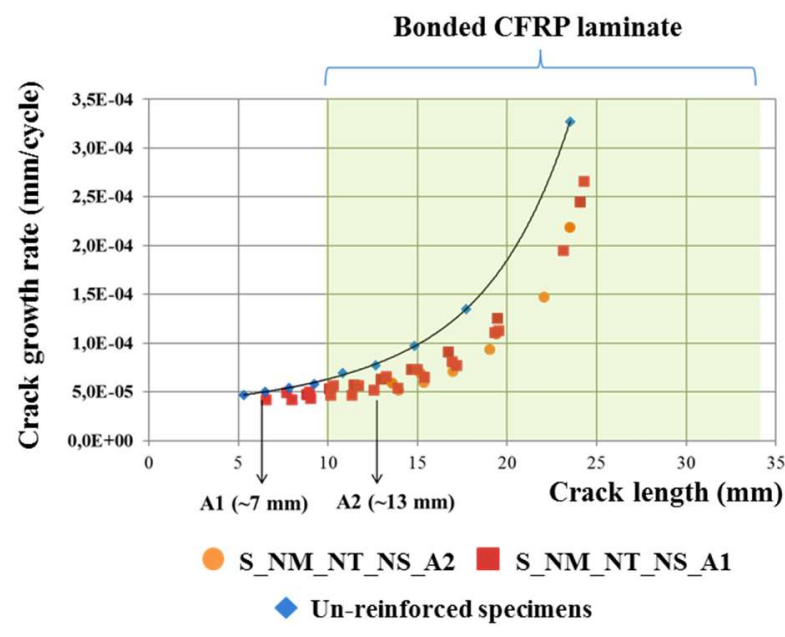

(b)

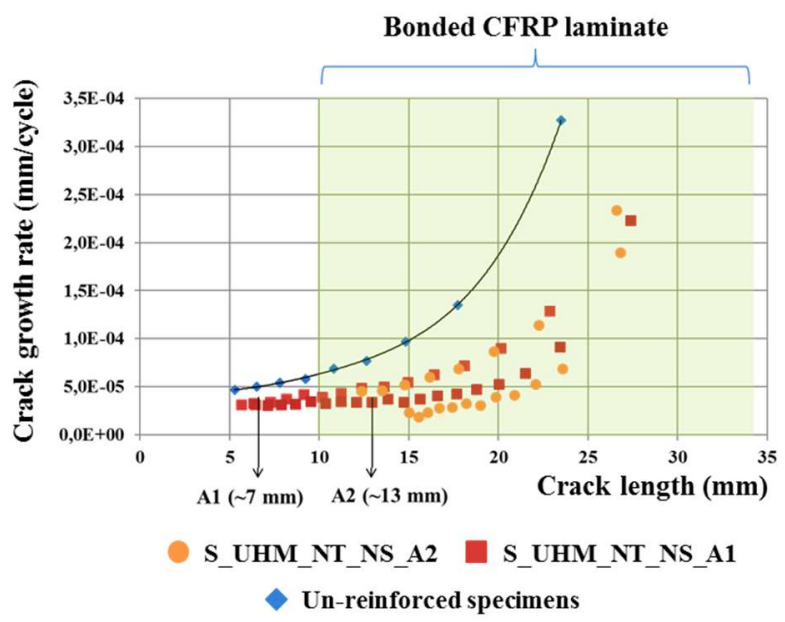

(d)

Figure 6 : Crack propagation curves for mild steel specimens: (a) S_NM_NP_DS specimens; (b) S_NM_NP_SS specimens; (c) S_NM_P(10kN)_SS specimens; (d) S_UHM_NP_SS specimens

The crack propagation curves for both un-strengthened and strengthened specimens with the same reinforcement configuration are very close to each other, reflecting the good repeatability of results. The small scattering can be attributed to faults in the CFRP application process, such as misalignment of CFRP, variation of adhesive thickness, or through misalignment of the specimen in the fatigue machine. For all strengthened specimens in figure 6, the fatigue crack growth curves clearly shows the effectiveness of the different reinforcement processes and configurations, whatever the initial crack length (A1 or A2). It is interesting to note that the fatigue crack propagates much more slowly when the plate is reinforced on both sides (symmetric reinforcement), with a final crack propagation length (at breaking point) longer that the other un-symmetric reinforced specimens. In fact, the CFRP strengthening delays the final fracture of the specimens (some of the loads is carried by the composites plates) and, for symmetric reinforcement configuration, no secondary bending effect is involved in crack propagation. 
Single-side repaired specimens with non-pre-stressed NM CFRP plate exhibited minor effects on the fatigue performance of cracked steel elements as already mentioned previously. When pre-stressed is applied to the CFRP plate, an immediate (even before the crack tip has reached the edge of the bonded CFRP plate) and significant reduction of the crack propagation rate was observed. In fact, pre-stressing CFRP plate produces a compressive force at the crack edges similar to the crack closure phenomenon. For single side repaired specimens with UHM CFRP, it is also interesting to note an immediate decrease of the crack propagation rate after applying bonded CFRP plate. In fact, high modulus CFRP laminate have a more restraining effect due to their high stiffness. Therefore, crack-opening displacement is also significantly reduced after applying CFRP plate.

Finally, it is important to report that for some specimens, secondary crack propagation at the opposite side was observed (see Figure 7). This secondary crack propagates very quickly (only a few beachmarks observable), but causes a reduction of the final crack propagation length of the main crack and consequently a decrease of the fatigue life.

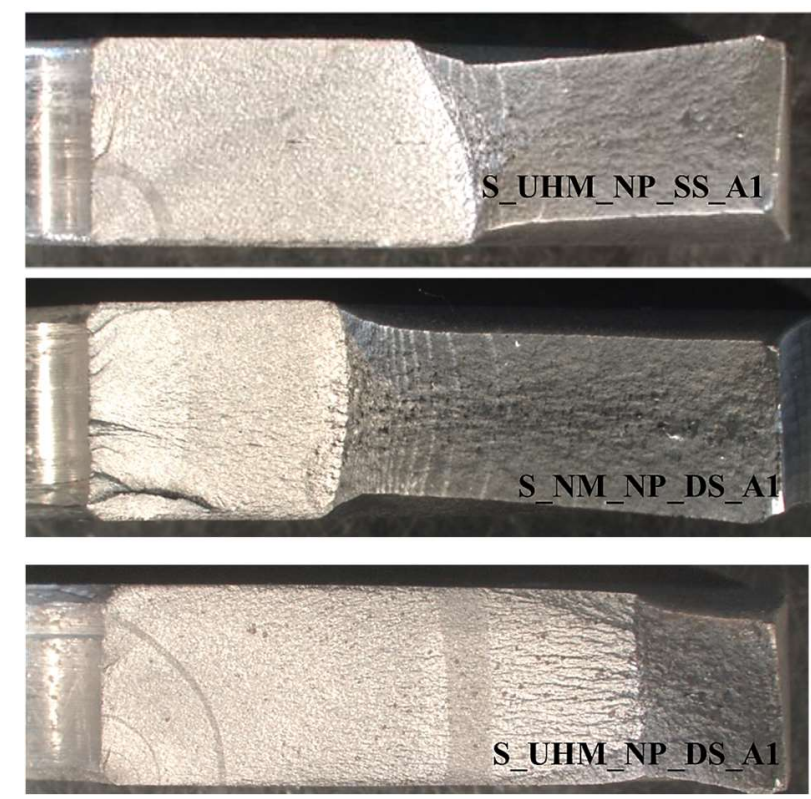

Figure 7: Secondary crack propagation at the opposite edge of the hole

For wrought iron specimens, crack front shape cannot be observed during propagation and the crack length was determined from the crack gauge bonded on the un-patched side (crack length at midthickness could not be recorded in that case). The fatigue crack growth curves are plotted for each specimen separately due to the wide heterogeneity of the results. All the results are shown in Figure 8.

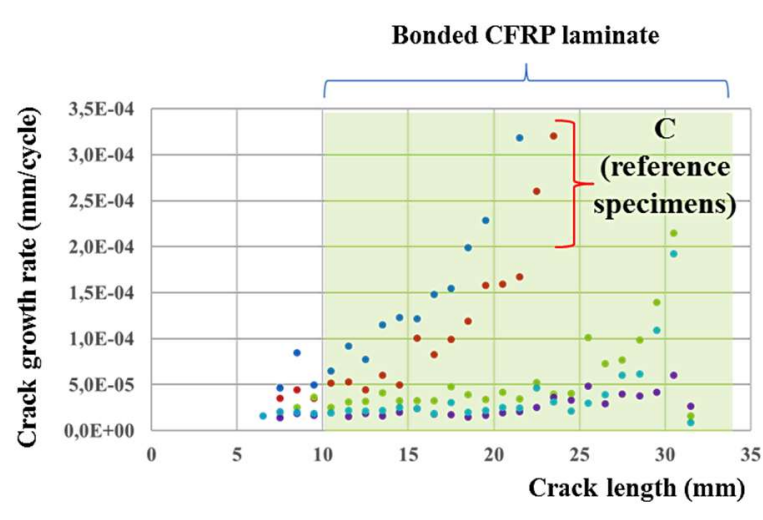

I_UHM_NP_SS_A1

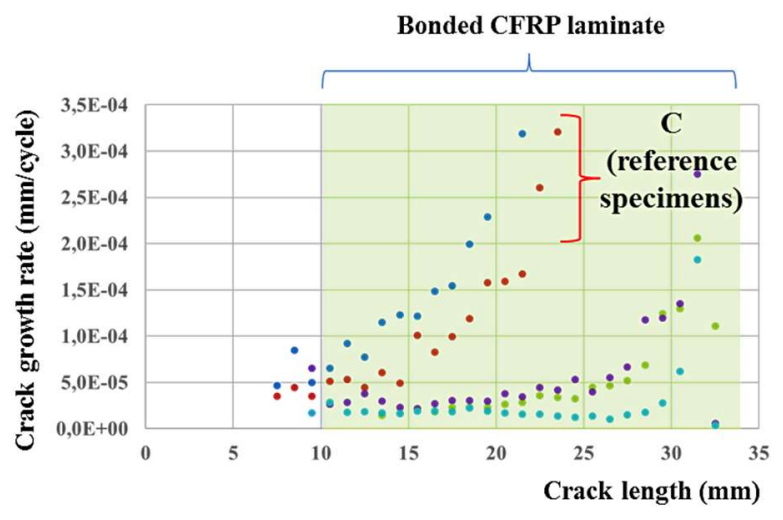

I_UHM_NP_SS_A2 
Figure 8 : Crack growth curves for wrought iron specimens: (a) I_UHM_NT_NS_A1 specimens; (b) I_UM_NT_NS_A2 specimens

The main result concerns the significant effectiveness of the strengthening, with an effective decrease of the crack propagation rate whatever the initial crack length (A1 or A2). Nevertheless, the wide heterogeneity of the results leads to extreme caution to the analysis of the results. In practice, the reinforcement of wrought iron bridges requires regular monitoring of the crack propagation in order to ensure the safety of the structure.

\section{c. Failure modes}

Three different failure modes were observed depending mainly on the CFRP reinforcement process and the reinforcement configuration. The failure mode for each specimen is listed in Table 2 for mild steel ones and Table 3 for wrought iron ones. CF stands for the cohesive failure in adhesive layer, CD for CFRP delamination (separation of some carbon fibers from the matrix) and CR for CFRP rupture.

\section{- NM CFRP-reinforced specimens :}

NM CFRP reinforcement was only studied for mild steel specimens and for both single-side and doubleside repaired specimens. In all cases, failure of NM CFRP-reinforced specimens was caused by cohesive failure in the adhesive layer, as illustrated in Figure 9. Binocular picture (left) and SEM (Scanning Electron Microscope) picture (right) were done. SEM of the bond fracture surface shows a typical fracture surface with ductile tearing, voiding and cavitation of the adhesive particles [33].

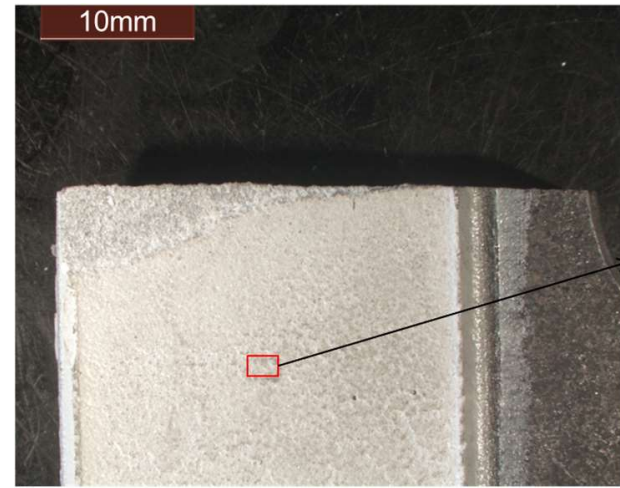

Binocular analysis - cohesive failure

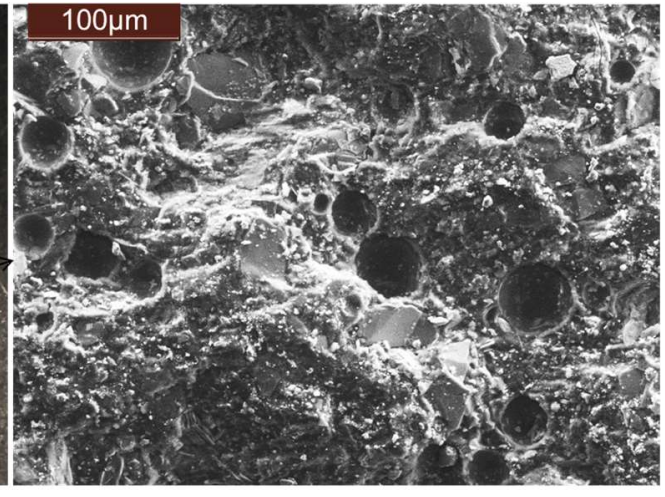

SEM analysis - cohesive failure

Figure 9 : Microscope analysis for NM CFRP-reinforced specimens

Due to the stress concentration at the fatigue crack tip, a debonding area around the fatigue crack tip can be observed for all NM reinforced specimens, see Figure 10. This debonding area corresponds to the propagation of a mode II fatigue crack at the steel/adhesive interface requiring lowest fracture energy than the mode I fatigue crack propagating in the strengthened steel plate [34].

For single-side repaired specimens, the debonding area shows a cone shape, with a larger size at approximately mid-width of the CFRP laminate. While, for double side repaired specimens the debonding area size is smaller and show more a trapezoidal shape.

The increase of crack shape for single-side repaired specimens, as crack propagates, can be mainly explained by the un-symmetric repairing configuration that leads to eccentricity of the load (displacement of neutral axis) and to a secondary bending in the plate. 

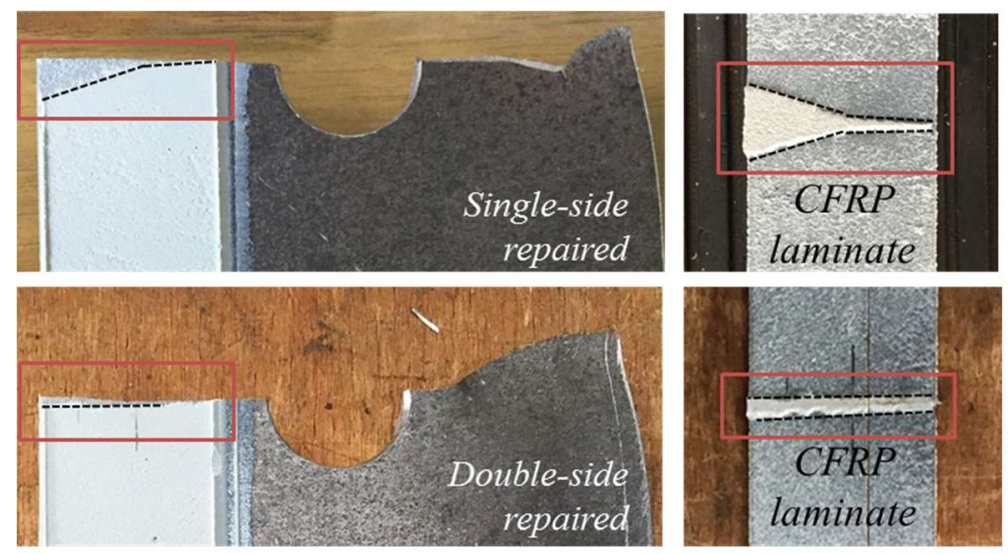

Figure 10 : Final debonding shapes after failure of single-side (top) and double-side (bottom) NMstrengthened specimens

Colombi et al., [35, 36], for center cracked metallic plates (two symmetric notches at a center hole) reinforced by CFRP bonded on both sides of the specimens, have shown that the debonding shape could be well approximated by an ellipse with an aspect ratio of 1/5 (ratio of minor to major axes). In our case, the debonding shape looks more like the debonding shape observed for double-edge-notched specimens, both reinforced on one side (cone shape observed by Baker [37, 38]) or on both sides of the plate (trumpet shape observed by Huawen et al., [39]).

In the case of double-edge-notched specimens, the crack propagation from the notches often occurs in an un-symmetric way, that is to say, a main crack (from one of both notches) propagates in almost all the width of the plates, while the second crack (from the other notch) remains about the order of a few millimeters. Thus, as for our specimens, the redistribution of stresses becomes un-symmetric in the width of the plate, and the same phenomena of secondary bending occurs for single-side repaired specimens. In conclusion, the geometry of the specimens and the reinforcement configuration (singleside or double-side repairing) seems to have a wide influence on the debonding area (shape and size). This observation is of great importance since the Stress Intensity Factor (SIF) at crack tip depends on the debonded zone (a smaller debonded area leads to a better utilization of the CFRP plate and thus to a decrease of SIF at crack tip).

\section{- UHM CFRP-reinforced specimens :}

Single-side UHM reinforcement configuration was tested for both mild steel and wrought iron specimens. Regarding the failure mode of these specimens, a more complex mechanism of failure was observed with a combination of different debonding mechanisms, as illustrated in Figure 11.

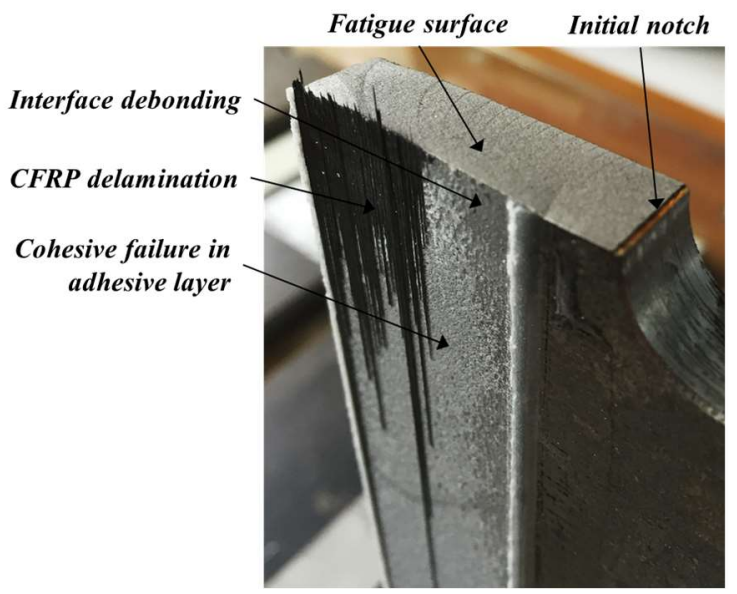

(a)

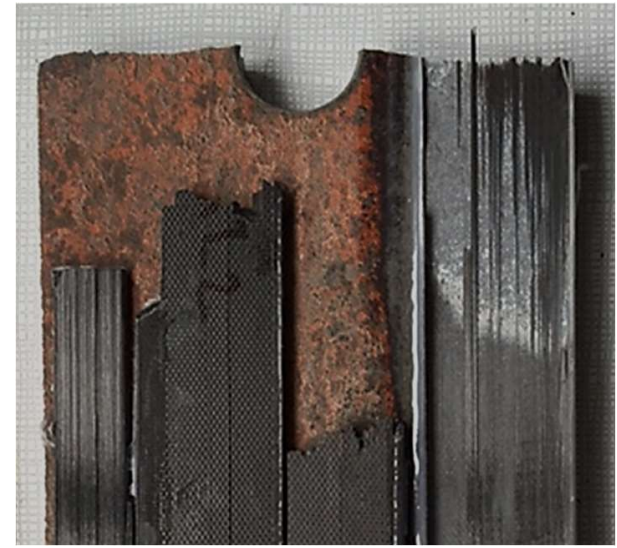

(b)

Figure 11: Combination of failure modes for single-side UHM-reinforced specimens: (a) mild steel specimens; (b) wrought iron specimens 
At the beginning of the propagation stage, a mixed failure mode was observed with both adhesive failure at the interface between the adhesive and the metallic plate, and cohesive failure in the adhesive layer. This mixed failure mode, in the first stage of propagation, could be highlighted by the SEM analysis for mild steel specimens, as illustrated in Figure 12. The metallic surface (sandblasted surface) is represented by the white zone while the thin layer of adhesive embedded in the surface roughness is represented by the dark area (voiding and cavitation of the adhesive particles are thus visible).
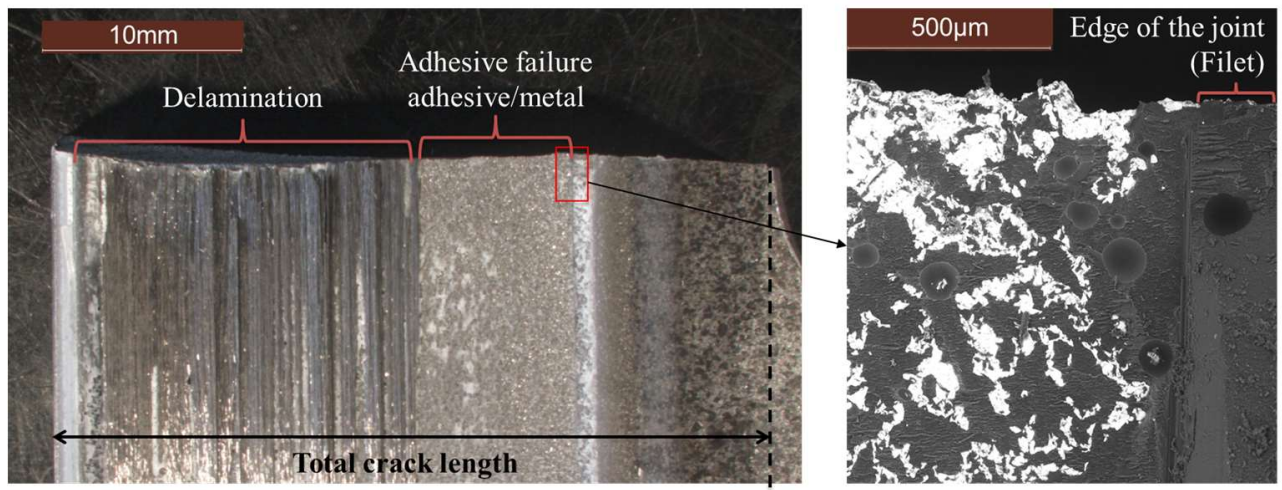

Figure 12: Microscope analysis for single-side UHM CFRP-reinforced mild steel specimens

After a certain crack length (around half the total length of the crack from all specimens), the failure process is then dominated by delamination of the UHM CFRP laminate (separation of some carbon fibers from the resin matrix) for both mild steel and wrought iron specimens. This observation seems to echo the first observation done on single-side repaired specimens with NM CFRP laminate (increase of debonded area at mid-width of the CFRP laminate, see Figure 10). Thus, the un-symmetric reinforcement configuration (CFRP laminate bonded on one side of the plate) seems once again to have a major effect regarding the failure mode.

\section{d. Strain evolution for pre-stressed NM specimens}

Figure 13 plots the development of steel and laminate strain versus the number of cycles, until complete failure of the specimen, for pre-stressed NM CFRP plate bonded on one side of the steel plate. The results were very similar for all specimens, so only one specimen is presented below.

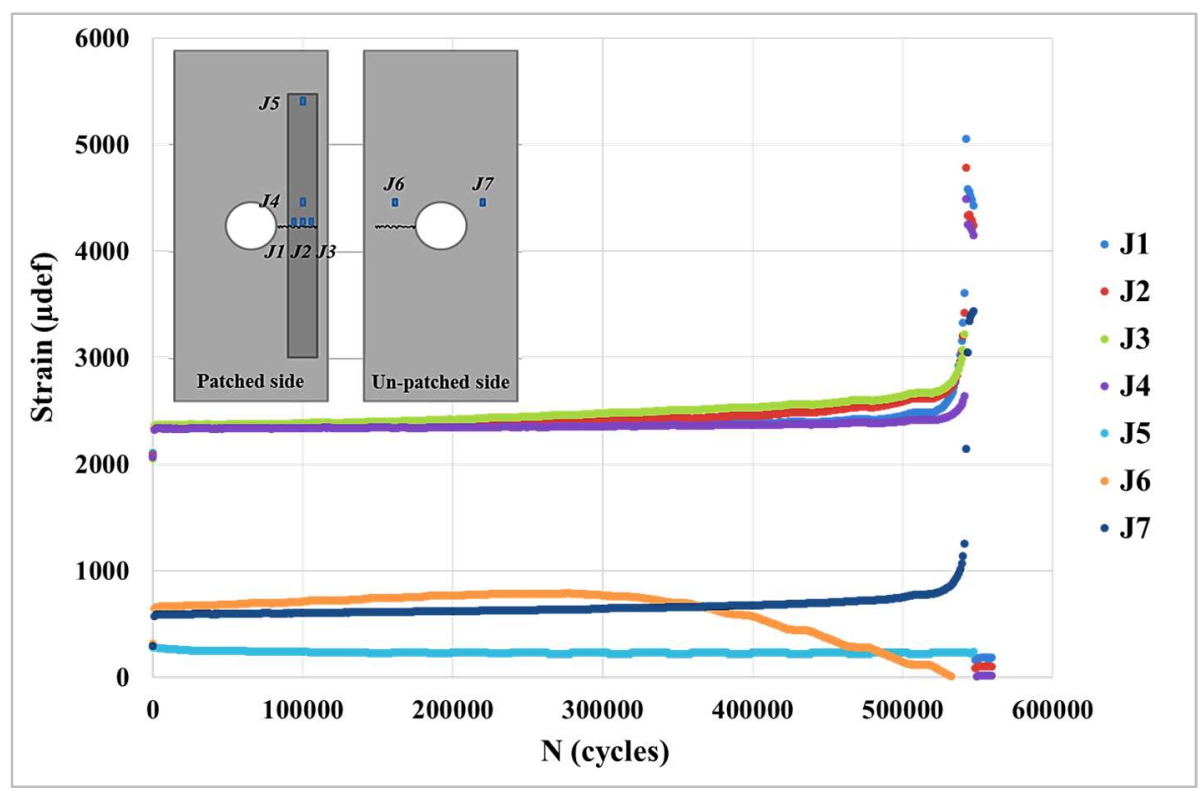

Figure 13: Strain deformation evolution versus number of cycles during crack propagation for NM_P(10kN)_SS_A1 specimens 
For all strain gauges bonded on the CFRP laminate (J1 to J5), strain evolution remains low through most of the fatigue life of the specimen. For strain gauges J1 to J3 located near the crack path, the strain level becomes more and more significant in the last fatigue cycles, corresponding to a high crack propagation rate and a loss in cross section area of the steel plate. The difference of measured strain for these three gauges seems to be an indicative of the stress eccentricity in the steel plate during crack propagation and seems consistent with the development of the debonding cone shape highlighted in figure 10. For strain gauges $\mathrm{J} 4$ and J5, furthest of the crack and of the hole, strain level remains almost unchanged until the complete failure of the specimens. Finally, for strain gauges J6 and J7 bonded on the metallic plate, the strain evolution clearly highlights the asymmetry of stresses on both sides of the hole, due to the propagation of only one crack at the edge of the hole. Reduction in strain level during the crack propagation is due to the loss in cross section area (the releases some load).

Strains patterns observed in figure 13, are similar to those of others studies led by Täljsten et al., [21] and Huawen et al., [39], considering double side repaired steel plates by pre-stressed CFRP laminates. As expected, the stress redistribution mainly occurred in the regime of high crack growth rates (at the end of the lifetime of samples), and the results showed reduced steel stresses and increased laminate due to crack growth.

\section{Conclusions and perspectives}

Fatigue crack growth behavior of cracked metallic plate reinforced by bonded CFRP laminates was investigated through experimental study. This study involved fatigue behavior of $10 \mathrm{~mm}$ thick mild steel and $7 \mathrm{~mm}$ thick wrought iron specimens, with one fatigue crack emanating from a center hole, and reinforced with unidirectional NM (Normal Modulus) and UHM (Ultra High Modulus) CFRP laminates, pre-stressed or non-pre-stressed, bonded on one side or both sides of the metallic plate. The following conclusions were reached:

- The application of adhesively bonded CFRP laminates significantly reduces crack growth rate and prolongs fatigue life of the specimens.

- For CFRP-reinforced mild steel specimens, the fatigue life was increased by factors ranging from 1.25 to 2.27 . The most important efficiency was obtained for double-side repaired specimens, although this reinforcement configuration is not representative of real riveted assemblies. For single-side repaired specimens, pre-stressing the CFRP laminate with normal modulus has a considerable effect on the fatigue life of the specimens. It is obvious that higher pre-stressing level will provide higher compressive stresses and thus better efficiency of the reinforcement. Nonetheless, a high pre-stress level needs reliable anchorage system and raises many issues regarding the durability of the assembly. In this context, the use of UHM CFRP plate seems to be a good solution and allows a considerable increase in fatigue life, comparable to the case of pre-stressed NM CFRP laminate.

- For UHM CFRP-reinforced wrought iron specimens, the fatigue life was increased by factors ranging from 2.19 to 4.27 . A high dispersion of the results was observed for all specimens, mainly due to the microstructure of the material.

- Three different failure modes were observed depending on the reinforcement configuration. For all specimens reinforced with normal modulus CFRP, cohesive failure in the adhesive layer was observed. While, for specimens reinforced with ultra high modulus CFRP, a mixed failure mode was observed involving delamination and CFRP rupture.

Further investigations are now needed regarding the evaluation of the stress intensity factor (SIF) at the crack tip for CFRP-reinforced specimens. Determination of the modified SIF for each reinforcement configuration will provide a reliable valuation method of efficiency of CFRP reinforcement. Such method will be greatly useful for practicing engineers and can be adapted to other element geometries (particularly riveted connections).

\section{ACKNOWLEDGEMENT}


The authors gratefully acknowledge the financial support and material provided by the French national rail company SNCF. They also acknowledge SIKA, Freyssinet and Fyfe for providing reinforcement materials.

\section{BIBLIOGRAPHY}

[1] Sustainable Bridges Project (2007). "Improved Assessment Methods for Static and Fatigue Resistance of Old Steel Railway Bridges", Background document D4.6.

[2] Brühwiler, E., Smith, I., and Hirt, M. A. (1990). "Fatigue and fracture of riveted bridge members", Journal of Structural Engineering, vol. 116, no. 1, pp. 198-214.

[3] Liechti, P., Josi, G., and Kunz, P. (1997). "Ermüdungsversuche an genieten vollwandträgern”, Research report 367, Ecole Polytechnique Fédérale De Lausanne ICOM.

[4] Haghani, R., Al-Emrani, M., and Hesmati, M. (2012). "Fatigue-Prone Details in Steel Bridges", Buildings, vol. 2, no. 4, pp. 456-476.

[5] Bocciarelli, M., Colombi, P., Fava, G., and Poggi, C. (2009). "Fatigue performance of tensile steel members strengthened with CFRP plates", Composite Structures, vol. 87, no.4, pp. 334-343.

[6] Colombi, P., and Fava, G. (2012). "Fatigue behavior of tensile steel/CFRP joints", Composite Structures, vol. 94, no. 8 , pp. 2407-2417.

[7] Hollaway, L.C., and Cadei, J. (2002). "Progress in the technique of upgrading metallic structures with advanced polymer composites", Progress in Structural Engineering and Materials, vol.4, no. 2, pp. 131-148.

[8] Shaat, A., Schnerch, D., Fam, A., and Rizkalla, S. (2004). "Retrofit of Steel Structures Using Fiber Reinforced Polymers (FRP): State-of-the-Art", Transportation Research Board (TRB) Annual Meeting, Washington, DC, USA.

[9] Cadei, J.M.C., Stratford, T.J., Duckett, W.G., and Hollaway, L.C. (2004). "Strengthening metallic structures using externally bonded fibre-reinforced polymers", Construction Industry Research and Information Association. [10] Zhao X.L., and Zhang L. (2007). "State-of-the-art review on FRP strengthened steel structures", Engineering Structures, vol.29, pp. 1808-1823.

[11] Moy, S. (2011). "Case studies : FRP repair of steel and cast iron structures in Great Britain", FRP International, vol. 8, no. 3, pp. 5-8.

[12] Miller, T.C., Chajes, M.J., Mertz, D.R., and Hastings, J.N. (2001). "Strengthening of a steel bridge girder using CFRP plates", Journal of Bridge Engineering, vol. 6, no.6, pp. 514-522.

[13] Bassetti, A., Nussbaumer, A. and Hirt, M. A. (2000). "Crack repair and fatigue life extension of riveted bridge members using composite materials", Bridge Engineering Conference, ESE-IABSE-FIB, Sharm El Sheikh, vol. 1, pp. 227238.

[14] Tavakkolizadeh, M. and Saadatmanesh, H. (2003). "Fatigue Strength of Steel Girders Strengthened with Carbon Fiber Reinforced Polymer Patch", Journal of Structural Engineering, pp.186- 196.

[15] Zheng, Y., Ye, L.P., Lu, X.Y. and Yue, Q.R. (2006). "Experimental study on fatigue behavior of tensile, steel plates strengthened with CFRP plates", Proceedings of Third International Conference on FRP Composites in Civil Engineering (CICE 2006), Miami, USA, 13-15 December, pp.722-736.

[16] Liu, H., Al-Mahaidi, R. and Zhao X.L. (2009). "Experimental study of fatigue crack growth behaviour in adhesively reinforced steel structures", Composite Structures, vol. 90, no. 1, pp. 12-20.

[17] Kim, Y.J. and Harries, K.A. (2011). "Fatigue behavior of damaged steel beams repaired with CFRP strips", Engineering Structures, vol. 33, pp.1491-1502.

[18] Yu, Q.Q., Zhao, X.L., Al-Mahaidi, R., Xiao, Z.G., Chen, T. and Gu, X.L. (2014). "Tests on cracked steel plates with different damage levels strengthened by CFRP laminates", International Journal of Structural Stability and Dynamics, vol. 14, no. 6, $26 \mathrm{p}$.

[19] Bassetti, A. (2001). "Lamelles Précontraintes en Fibres Carbone pour le Renforcement de Ponts Rivetés Endommagés par Fatigue", Ph.D. thesis, Swiss Federal Institute of Technology, EPFL, Lausanne, Switzerland.

[20] Hansen, C.S., Schmidt, J.W. and Täljsten, B. (2007). "Strengthening of old metallic structures in fatigue with CFRP materials", Asia-Pacific Conference on FRP in structures (APFIS 2007).

[21] Täljsten, B., Hansen, C.S. and Schmidt, J.W. (2009). "Strengthening of old metallic structures in fatigue with prestressed and non-prestressed CFRP laminates", Construction and Building Materials, vol. 23, pp. 1665-1677.

[22] Wu, C., Zhao, X.L., Al-Mahaidi, R., Emdad, M.R. and Duan, W. (2012). "Fatigue tests of cracked steel plates strengthened with UHM CFRP plates", Advances in Structural Engineering, vol. 15, pp. 1801-1816.

[23] Fawzia, S., Almahaidi, R. and Zhao, X. (2006). "Experimental and finite element analysis of a double strap joint between steel plates and normal modulus CFRP”, Composite Structures, vol. 75, pp. 156-62.

[24] Jones, S.C. and Civjan, S.A. (2003). "Application of fiber reinforced polymer overlays to extend steel fatigue life", Journal of Composites for Construction, ASCE, vol. 7, no. 4, pp. 331-338.

[25] Lepretre, E. (2016). "Efficacité du renforcement par composites collés vis-à-vis de la propagation de fissures de fatigue pour une application aux structures rivetées", PhD Thesis, UBL-Ecole Centrale Nantes, France. 
[26] Lepretre, E., Chataigner, S., Dieng, L., Gaillet, L., Gagnon, A., Roth, J. and LeRoy, C. (2016). "Experimental characterization of different adhesively bonded composite reinforcement processes for old steel structures", Proceedings of Structural Faults and Repair, Edinburg.

[27] Lee, W.Y. and Lee, J.J. (2004). "Successive 3D FE analysis technique for characterization of fatigue crack growth behavior in composite-repaired aluminum plate", Composite Structures, vol. 66, pp. 513-520.

[28] Emdad, R. and Al-Mahaidi, R. (2015). "Effect of prestressed CFRP patches on crack growth of centre-notched steel plates", Composite Structures, vol. 123, pp. 109-122.

[29] Hosseini, A., Ghafoori, E., Motavilli, M., Nussbaumer, A. and Zhao, X.L. (2017). "Mode I fatigue crack arrest in tensile steel members using prestressed CFRP plates”, Composite Structures, vol. 178, pp. 119-134.

[30] Wang, W.W., Dai, J.G., Harries, K.A. and Zhang, L. (2014). "Prediction of prestress losses in RC beams externally strengthened with prestressed CFRP sheets/plates”, Journal of Reinforced Plastics and Composites, vol. 33, no. 8, pp. 699-713.

[31] Colombi, P., Bassetti, A. and Nussbaumer, A. (2003a). "Analysis of cracked steel members reinforced by pre-stress composite patch", Fatigue \& Fracture of Engineering Materials \& Structures, vol. 26, no. 1, pp. 5966.

[32] Ratwani, M.M. (1979). “Analysis of cracked, adhesively bonded laminated structures”, AIAA Journal, vol. 17, no. 9, pp. 988-994.

[33] Casas-Rodriguez, J.P., Ashcroft, I.A. and Silberschmidt, V.V. (2008). "Delamination in adhesively bonded CFRP joints: standard fatigue, impact-fatigue and intermittent impact", Composites Science and Technology, vol. 68, no. 12, pp. 2401-2409.

[34] Hansen, C.S., Jensen, P.H., Dyrelund, J. and Täljsten, B. (2009). "Crack propagation on ESE(T) Specimens Strengthened with CFRP Sheets", In Advanced Composites in Construction, Conference Proceedings, 1st edition, pp. $402-413$.

[35] Colombi, P., Bassetti, A. and Nussbaumer, A. (2003b). “Crack growth induced delamination on steel members reinforced by prestressed composite patch", Fatigue \& Fracture of Engineering Materials \& Structures, vol. 26, no. 5, pp. 429-438.

[36] Colombi, P., Bassetti, A. and Nussbaumer, A. (2003c). "Delamination effects on cracked steel members reinforced by prestressed composite patch", Theoretical and Applied Fracture Mechanics, vol. 39, no. 1, pp. 6171.

[37] Baker, A.A. (1993). "Repair efficiency in fatigue-cracked aluminium components reinforced with boron/epoxy patches", Fatigue \& Fracture of Engineering Materials \& Structures, vol. 16, vo. 7, pp. 753-765.

[38] Baker, A.A. (1995). "Bonded Composite Repair of Metallic Aircraft Components - Overview of Australian Activities”, $A G A R D-C P-550$, Paper 1, pp. 1-14.

[39] Huawen, Y., König, C., Ummenhofer, T., Shizhong, Q. and Plum, R. (2010). "Fatigue Performance of Tension Steel Plates Strengthened with Prestressed CFRP laminates", Journal of Composites for Construction, vol. 14, no. 5, pp. 609-615. 